\title{
Comunicação comunitária e jornalismo cidadão: diferenças teóricas e a apropriação mercadológica
}

\author{
Community communication and citizen journalism: theoretical differences and \\ market appropriation
}

\section{Thays Helena Silva Teixeira}

Bolsista da Coordenação de Aperfeiçoamento de Pessoal de Nível Superior (Capes), mestranda em Comunicação pela Universidade Federal do Piauí (UFPI), em Teresina, Piauí. Vinculada à linha de Processos e Práticas em Jornalismo, Teresina, PI - Brasil , e-mail: thays.teixeira1@hotmail.com

\section{Resumo}

Por meio de apresentação sistemática dos conceitos sobre comunicação comunitária e jornalismo cidadão, busca-se compará-los de modo a identificar divergências e semelhanças. A proposta é verificar que elementos os aproximam e os distanciam na pesquisa em comunicação e como esses elementos atingem o processo de produção de conteúdo nas empresas de comunicação ou são apropriados por elas. Pesquisa bibliográfica de abordagem dialética e que não se fecha nos termos apresentados, constitui espaço de debate do ponto de vista epistemológico. Conclui-se que esses conceitos da comunicação estão em constante transformação visando a novo formato de produção de conteúdos, de fontes participativas e distribuição de novas formas de produtos midiáticos, e que acabam sendo absorvidas pela lógica de mercado, mas que apresentam diferenciações fundamentais. Os conceitos ainda conservam sua validade teórica.

Palavras-chave:Jornalismocidadão. Comunicaçãocomunitária. Participação.Mercado da comunicação. Fontes.

\section{Abstract}

Through systematic presentation of concepts on community communication and citizen journalism, this paper seeks to compare them in order to identify differences and similarities. The proposal is to verify which elements approximate 
and distance them in communicational research and how these elements affect the process of content production in media companies, or are appropriated by them. Literature research with dialectical approach is not closed in the terms presented, it constitutes space for debate from the epistemological point of view. It is concluded that these concepts of communication are constantly changing aiming at new format of content production, participatory sources and distribution of new forms of media products, and they end up being absorbed by the market logics, but have fundamental differences. The concepts still preserve their theoretical validity.

Keywords: Citizen journalism. Community communication. Participation. Communication market. Sources.

\section{Começando a participar}

O jornalismo na contemporaneidade está em processo de ressignificação. Isso se torna evidente com o surgimento de infinidade de conceitos teóricos para caracterizar um ou outro formato de produção jornalística. Nessa ambientação, o jornalismo adquire diferentes características e também diversificadas definições. Em revisão sobre os modelos de jornalismo, Farooq Kperogi (2011) apresenta cinco gêneros de jornalismo.

O primeiro, jornalismo tradicional, referindo-se ao formato praticado pelos jornalistas profissionais, com a figura do gatekeeper. Nesse modelo, há uma exacerbada preocupação com a audiência e a participação élimitada, as exceções são as cartas enviadas ao editor (KPEROGI, 2011, p. 316). O segundo gênero, jornalismo público, também chamado de jornalismo cívico, já aproxima mais o produtor de notícias do cidadão. Nesse formato, já há uma preocupação com a participação da comunidade nas decisões do que se constitui como notícia e de como ela será apresentada. Ainda assim, a figura do gatekeeper é destinada aos jornalistas profissionais. No terceiro, o jornalismo interativo, Kperogi (2011, p. 317) aponta que não existe um grande distanciamento em relação ao gênero descrito anteriormente. Com o formato interativo, a produção jornalística se aproximaria ainda mais do cidadão, que já pode interferir diretamente na estrutura, e essa interatividade pode ser tanto de conteúdo quanto interpessoal. As ligações telefônicas e a internet são os grandes responsáveis por essa aproximação. No jornalismo participativo, o quarto gênero descrito por Kperogi (2011,p.319), os usuários não apenas interagem com a notícia e com os jornalistas profissionais, mas também participam de alguma forma desse processo produtivo. Nesse modelo, a internet também é o elemento desencadeador da participação; os webblogs são os exemplos mais comuns, cita o autor. No quinto gênero, o jornalismo cidadão, a participação do cidadão já é direta e eles se tornam produtores de conteúdos que não estão vinculados aos meios de comunicação tradicionais. (KPEROGI, 2011, p. 320). Ainda sobre as bases da participação do cidadão, encontramos outro conceito, o de comunicação comunitária (PERUZZO, 2006b), em que a figura do produtor de notícias também é o cidadão, assim como no último gênero descrito por Kperogi (2011).

Mesmo com as variações de termos, eles ainda não se esgotam, mas de fato representam modelos jornalísticos diferenciados, em que a participação popular é um dos propósitos. Dentro destes pressupostos, de que os conceitos não estão fechados e que carregam consigo um ranço de indefinição, a variabilidade de termos torna-se mais forte, causando certa confusão epistemológica sobre a que ou qual modelo tais conceitos dizem respeito. A exemplo desse estado confusional, temos os dois conceitos teóricos que serão guias para essa discussão: a comunicação comunitária e o jornalismo cidadão. Se a participação do consumidor de informações na produção é evidente nos dois modelos, por que eles são diferentes, ou de fato não são? A diferenciação desses tipos é relevante porque se costuma mencionar esses modelos como se referissem ao mesmo tipo produtivo, o que não se verifica de fato quando se consideram suas caracterizações conceituais, como consta mais adiante.

Abordaremos o conceito jornalismo cidadão como sendo construído nos parâmetros do open source ou o que Targino (2009, p. 51) chama de "um canal de fonte aberta, ou jornalismo cidadão". E para a noção conceitual de jornalismo comunitário (ou mais propriamente a comunicação comunitária), 
as categorias de participação ativa e ampliação da cidadania, como reforça Cicília Peruzzo (2006a), aparecem com mais ênfase. Em termos gerais, o que se pretende é mostrar algumas conceituações destas duas formas epistemológicas do fazer comunicacional e como elas apresentam semelhanças e também divergências cruciais que colocam os dois modelos em patamares diferentes, tanto epistemologicamente quanto como referências à lógica de mercado, mas, ainda assim, estão fundamentados em elementos teóricos relevantes.

Abordam-se as fontes como "fazedores da notícia" (TARGINO, 2009, p. 53) porque, nas duas formas revisadas do estudo da comunicação, as fontes se constituem como elementos condicionantes, tanto para o que se chama de jornalismo cidadão como para comunicação comunitária, uma semelhança substancial nesses dois formatos.

Nessa avaliação, as questões metodológicas prezam pela dialética, visto que os termos abordados estão mergulhados em elementos de contradição. Como procedimento, usa-se a pesquisa bibliográfica, no sentido de pontuar a caracterização de cada modelo conceitual de jornalismo debatido.

\section{Jornalismo cidadão}

Produzir notícias. Este parece ser o papel do jornalista, uma atividade que historicamente foi delegada a esse profissional. No entanto, com a fetichização das notícias (MORETSHOM, 2006), que se constitui na sua transformação em mercadorias, transformando-as em produto do capitalismo e moeda de troca das empresas jornalísticas, passaram a surgir formas de resistências. Elas são vinculadas principalmente às tecnologias digitais e considerando-as como algo libertário. Com o advento da internet, novas rotinas jornalísticas foram incorporadas e a produção de notícias saiu exclusivamente da mão dos profissionais do jornalismo. "São produtores e produtoras de mídia independentes" (TARGINO; CARVALHO; GOMES, 2008, p. 53). Essa independência não está necessariamente vinculada a determinado grupo, ou ao reconhecimento de uma comunidade em específico.

A produção de notícias que assim se fundamenta propõe novo fazer jornalístico que altera as rotinas produtivas que são características dos meios de comunicação tradicionais, os quais utilizam somente os jornalistas para fabricar notícias e informações. Essas novas formas laborais alteram a produção de conteúdos jornalísticos e sua distribuição é realizada de modo diferenciado, que não põe fim ao trabalho do jornalista (profissional especializado), mas que acrescenta uma nova gama de pessoas que também podem fazer notícias, prezando pela livre expressão e fugindo dos padrões mercadológicos. Essa caracterização é o que se denomina de "jornalismo cidadão", ou "jornalismo de fonte aberta", e o entendimento conceitual adotado nesta discussão. A prática é mais comum nos meios de comunicação que estão presentes na internet, pela facilidade de acesso.

Para concretizar metas tão amplas, fundamenta-se na filosofia de publicação aberta, ou seja, veiculação de informações no espaço virtual, automaticamente, por meio de um computador conectado à Internet. É mais que simples possibilidade tecnológica. Configura-se como veículo de ampla repercussão social, que impulsiona a democratização de informações, em qualquer formato (texto, áudio, imagem) e a custo zero, geradas por indivíduos "comuns", independentemente de características individuais e sociais. (TARGINO; CARVALHO; GOMES, 2008, p. 52).

O que destaca essa produção de notícias é que o indivíduo, aqui cidadão, pode livremente colocar em voga sua voz, e propor uma forma diferente de compreender as informações, tornando-se uma alternativa.

Targino, Carvalho e Gomes (2008) fazem um estudo minucioso sobre o jornalismo cidadão proposto pelo Centro de Mídia Independente do Brasil (CMI Brasil). Nesse estudo de caso, os autores analisam como funciona a estrutura do site e ressaltam as características que são comuns para a produção de um jornalismo do tipo cidadão. Na análise, eles identificam características de um meio de comunicação que pratica o jornalismo de fonte aberta. O exemplo do CMI Brasil é válido para a caracterização da prática, de um modo geral, de como se costuma operar em espaços de mídia independente. Dessa maneira, os indivíduos que têm acesso ao canal podem enviar suas informações em diversos formatos, dentre os quais podem ser citados: 
a) relatos sobre o cotidiano dos/as oprimidos/ as; b) relatos de novas formas de organização (como o Movimento Passe Livre [...], zapatistas no México, piqueteiros na Argentina, [...]); c) denúncias contra o Estado e as corporações; d) iniciativas de comunicação independente ([...] rádios e TVs livres e comunitárias, murais e jornais de bairro etc.); e) análises sobre a mídia; f) análises sobre movimentos sociais e formas de atuação política; g) produção audiovisual que vise a (sic) transformação da sociedade ou que retrate as realidades dos oprimidos ou as lutas dos novos movimentos (CMI BRASIL, 2007 apud TARGINO; CARVALHO; GOMES, 2008, p. 54).

Mesmo os autores fazendo análise específica, esses tipos de conteúdos são típicos do jornalismo cidadão. A forma como eles são enviados é outro ponto que também se destaca. O conteúdo não passa por edição, nem pode ser alterado, no caso do CMI, conforme aponta o estudo.

O que é postado no site também é livre e se fundamenta no copyleft (cópia sem restrições). Essa ressalva éindicada pelos autores que realizaram o trabalho com o Centro de Mídia Independente. Os autores também pontuam que o CMI Brasil possui um grupo editorial que avalia o conteúdo, e existem algumas restrições, que se dão quando o conteúdo envidado fere algum preceito legal ou foge à ética.

Dentre todas essas observações, mesmo por vias de um estudo de caso, pode-se compreender a perspectiva do jornalismo cidadão como aquele realizado pelo indivíduo. Não se percebe necessariamente uma identidade coletiva, muito menos um lócus territorial definido. Cada pessoa, dentro dessas observações, é responsável pelo que publica.

Outro campo também pode ser validado: o da interatividade. A interatividade permite que os novos produtores de informações possam trocar experiências entre si promovendo discussões nesses espaços reconhecidamente livres. São comentários, emails, linhas de bate-papo, entre outras, que podem colocar os fazedores das informações em contatos diretos um com os outros e ampliando as redes de atuação desses conteúdos desvinculados das mídias de massa. Assim, o jornalismo cidadão favorece ao exercício da cidadania porque reitera as lutas pelos direitos civis e políticos e também porque reivindica o cumprimento de deveres. Estes são posicionamentos diante dos meios gerenciados por forças hegemônicas.

\section{Transformações no webjornalismo: das empresas à fonte aberta}

Com o advento da internet, o jornalismo se apropriou do espaço e se transformou em algo mais interativo e tecnológico. Assim, a internet passou a ser conhecida como o meio cidadão. Os leitores/ usuários deixaram de ser figuras passivas e se tornaram indivíduos atuantes e questionadores.

Assim, o que vemos hoje, de novidade, é que a internet interliga os indivíduos e os possibilita formar o seu próprio habitat de comunicação sem, para isso, ter de passar por qualquer mediação. É, de fato, um plano de antagonismo com os sistemas de comunicação que a antecederam. Esse antagonismo ocorre porque a colaboração crescente dos usuários na produção de conteúdos para sites públicos e comuns na internet gera uma "nova audiência" em "novos meios de comunicação", que contêm conteúdos multimídia que complementam, subvertem ou ainda divergem daqueles emitidos pelos veículos da mídia de massa (MALINI, 2008, p. 2).

Foi nessa proposição de subversão que o jornalismo cidadão se instalou. Com esse propósito, o princípio do webjornalismo, que era fundamentado em um modelo tradicional como aquele desenvolvido nos meios de comunicação tradicionais (rádio, TV e impresso), um jornalismo de cunho empresarial, se modificou e passou a incorporar o usuário como participador das rotinas de produção de notícias.

Essas vertentes que se modificaram são conhecidas como "web. 1.0 e web. 2.0" (TARGINO; CARVALHO; GOMES, 2008, p. 60). Nessas modificações, as suas concepções passaram de um modelo empresarial (jornalismo tradicional) para um mais cidadão e também com o desenvolvimento tecnológico mais acentuado.

Independentemente das questões terminológicas, essas novas expressões demarcam as distinções entreaweb tradicionale esta, que se expandecomo rede social,privilegiando a participação do cidadão 
e dos grupos sociais à frente da produção de notícias. Isto exclui, teoricamente, o mercantilismo e reforça a intenção de um jornalismo voltado para a cidadania e/ou afeito aos valores "poéticos" do jornalismo brasileiro, em sua faseinicial, quando as ideias prevaleciam sobre as questões econômicas e mercantilistas, e a imprensa se impunha como serviço público a favor das coletividades e das tradições culturais e literárias. Ou seja, esta é a diferença fundamental entre web 1.0 e web 2.0: em lugar de anunciantes, voluntários; em lugar de empresários, pessoas comuns no gerenciamento dos espaços virtuais; em lugar do discurso oficial, a voz das coletividades; em lugar de lucro (exorbitante ou não), justiça (TARGINO; CARVALHO; GOMES, 2008, p. 57).

Com esse novo espaço, a consolidação do jornalismo cidadão pode acontecer. Contudo, isso não quer dizer que esse tipo de jornalismo não deva ser encarado com um olhar crítico. O desenvolvimento a caminho da valorização da cidadania está acontecendo, mas os desafios de inclusão ainda são grandes, principalmente em países como o Brasil, onde a diferença econômica e digital ainda é clara.

\section{Comunicação comunitária}

A relaçãodialética comunicação/comunidade é o elemento primordial na caracterização conceitual da comunicação comunitária. Esses conceitos, por sua vez, não se fecham; ao contrário, estão em situação de transformação, de ressignificação. Para entender a comunicação comunitária, é preciso evidenciar que a perspectiva de comunidade transcende a sua ideia tradicional vinculada principalmente às noções de ambiente físico e delimitado territorialmente. Nos tempos de revolução da internet, a apropriação de comunidade passou também ao campo digital, e o termo se modificou, ou melhor dizendo, se reconfigurou, não está necessariamente ligada à concepção geográfica.

Em uma construção histórica sobre a evolução das concepções a respeito de comunidade, Cicília Peruzzo (2006b) faz um apanhado sobre as diversas apropriações do termo. Ela parte de Ferdinand Tönnies com a vinculação da comunidade ao elemento rural, resultante de uma organização de vida orgânica, para daí seguirpara Dascal,Zimmermann, Buber, Maclever e Page, que afunilaram ainda mais as concepções sobre comunidade e, por fim, definir por si as características primordiais, ou que ela chama de "condições básicas" (PERUZZO, 2006b, p. 13) para existência de uma comunidade. Tais pré-requisitos são:

a) um processo de vida comum por meio de relacionamentos orgânicos e certo grau de coesão social;

b) autossuficiência (as relações sociais podem ser satisfeitas dentro da comunidade, embora não seja excludente);

c) cultura comum;

d) objetivos comuns;

e) identidade natural e espontânea entre os interesses e seus membros;

f) consciência de suas singularidades identificativas;

g) sentimento de pertencimento;

h) participação ativa; i) lócus territorial específico; e

i) linguagem comum.

Com esses requisitos, identifica-se por que a conceituação de comunidade é tão valorativa no entendimento da comunicação comunitária. Propõe-se um novo olhar para tais condições. Mesmo a noção de lócus territorial sendo importante, ela não necessariamente se configura como uma condição sine qua non, bem como todos os outros. Essa ressalva é válida porque, em tempos de novas tecnologias e de fim de determinadas barreiras por causa da internet, nem sempre todas as características estarão presentes e nem por isso o conceito de comunidade se perde. Ele é reconfigurado.

Destacar essa modificação é fundamental porque a comunicação comunitária se apropriou dessa reconfiguração e se modificou. A delimitação do termo comunidade, mesmo não sendo algo fácil ou unânime, é crucial. Quando absorvemos a comunidade e passamos a vê-la como algo que nos pertence, já estamos inseridos nela. É o elemento mais forte nessa definição. O pertencimento é o fator que leva à participação ativa, que por sua vez, é o elemento catalizador da comunicação comunitária. Mais adiante entenderemos porque a participação é tão vital para o desenvolvimento desse tipo comunicacional.

Importante agora é que, se não existe a concepção de pertencimento, a compreensão de comunidade pode se perder. Muitos exemplos poderiam ser 
citados, até de modo empírico. Se um indivíduo vai embora de sua terra natal por algum motivo (trabalho, estudo), mas, mesmo assim, continua identificando-se com ela e mantendo vínculos, mesmo que a distância (meios de comunicação, não necessariamente midiáti$\cos$ ), ele ainda é membro da comunidade e, portanto, se sente pertencendo ao local de origem, ou seja, não existe uma fixidez territorial.

Aborda-se a seguinte definição para o que venha a ser comunicação comunitária:

Caracteriza-se por processos de comunicação baseados em princípios públicos, tais como não ter fins lucrativos, propiciar a participação ativa da população, ter propriedade coletiva e difundir conteúdos com a finalidade de educação, cultura e ampliação da cidadania. Engloba os meios tecnológicos e outras modalidades de canais de expressão sob o controle dos movimentos e organizações sociais sem fins lucrativos (PERUZZO, 2006a, p. 9-10).

Pela observação citada, o empoderamento das concepções de comunidade acompanhado de novas tecnologias faz-se presente no que se compreende por comunicação comunitária, como anteriormente mencionado. Quando se vincula a comunidade aos meios de comunicação, nesse caso, midiáticos, ela absorve uma característica outra: a de transformação. Ou o que Raquel Paiva (2007, p. 137) fundamenta como "uma força contra-hegemônica".

Situa-se que a comunicação comunitária esteja ligada aos pequenos meios de comunicação, que inseriram uma multiplicidade de vozes e ampliaram a capacidade do indivíduo de propor comunicacionalmente suas necessidades e seus anseios. Aquele cidadão que era unicamente fonte dos grandes meios de comunicação se torna um elemento produtor de notícias ou informações e também gerenciador dos meios de comunicação, ativamente participativo. Rabelo (2006, p. 179) aponta para a "possibilidade das variadas vozes locais encontram ali um fórum aberto de debate" .

\section{Participação: característica primordial na comunicação comunitária}

Se a comunicação comunitária é balizada na contra-hegemonia, a participação ativa é primordial no funcionamento dos meios de comunicação do tipo comunitário. Compreende-se, então, que elas caminham lado a lado. Nessa caminhada, a participação passa por vários níveis, desde os níveis básicos até chegar aos mais elevados, a gestão dos próprios meios de comunicação.

A compreensão da participação ativa é necessária, uma vez que ela é responsável pela transformação prometida (identidade contra-hegemônica) pelos meios de comunicação comunitária. Com ela, o cidadão consegue produzir o que lhe é de interesse e da comunidade. A diferenciação da participação em níveis acontece porque os indivíduos pertencentes às comunidades não participam da mesma maneira nem com a mesma intensidade quando estão atuando dentro dos pequenos meios. Os meios costumam ser: rádios comunitários, jornais de bairros ou outros mecanismos que se utilizam das novas tecnologias para ampliar as vozes dos seus promotores, mais precisamente dos cidadãos.

Conforme descreve Peruzzo (2005), os (tais) níveis são definidos de forma a identificar como se desenvolve a participação dentro de cada meio de comunicação e como ela pode evoluir por vias de estratégias democráticas até que a comunidade possa gerenciar e produzir seus próprios conteúdos. As pessoas podem atuar de modo participativo das seguintes maneiras:

Participação nas mensagens: nível elementar da participação, no qual a pessoa dá entrevista, pede música, etc., mas não tem o poder de decisão sobre a edição e transmissão. Participação na produção e difusão de mensagens, materiais e programas: consiste na elaboração, edição e transmissão de conteúdos. Participação no planejamento: consiste no envolvimento das pessoas no estabelecimento das pessoas na política do meio comunicativo, na elaboração dos planos de formatos do meio e de programas, na elaboração dos objetivos e princípios de gestão e etc. Participação na gestão: consiste no envolvimento no processo de administração e controle de um meio de comunicação comunitária (PERUZZO, 2005, p. 11-12).

Com essas delimitações, compreende-se que a participação acontece desde o simples ato de mandar mensagens para os meios de comunicação até de fato decidir o que vai ao ar e como isso será feito. 
A participação é reiterada por parâmetros da autonomia e, em tese, deve acontecer de modo não manipulado, respeitando as necessidades das comunidades que representam. É importante ressaltar, nesse momento, que as primeiras concepções sobre a participação foram desenvolvidas por Utreras e reconfiguradas por Peruzzo em estudos posteriores (PERUZZO, 2005, p. 10).

As emissoras comunitárias são aquelas que, em geral, conseguem um maior nível de participação e/ou articulação e possuem espaços coletivos de decisão. Nem sempre conseguem reunir, ao mesmo tempo, a participação na programação e/ou na gestão (FERREIRA DE MELO; TORRES-MORALES, 2007, p. 11).

Entende-se que os níveis são uma evolução e, de certa forma, até tipos ideais e que os meios de comunicação comunitários ainda encontram na participação desafios para instrumentos de comunicação mais democráticos.

\section{Divergências e semelhanças entre o jornalísmo cidadão e comunitário}

Depois desse contato teórico com as principais concepções sobre o que são o jornalismo cidadão e a comunicação comunitária, podemos perceber que essas duas formas de desenvolvimento da comunicação social têm propósitos em comum, mas ainda assim apresentam divergências sobre como são elaborados o modo e a rotina produtiva.

A seguir, é apresentado um panorama das principais semelhanças e divergências identificadas. Essa separação é feita por uma questão didática, portanto abertas para seremassumidas com outro olhar. Reitera-se que os pontos identificados como divergentes e semelhantes são baseados nas construções teóricas apontadas anteriormente, o que não quer dizer que outros pontos possam ser acrescentados.

\section{Semelhanças: a aproximação das múltiplas vozes}

Para compreender de um modo mais sistemático as semelhanças entre o jornalismo cidadão e a comunicação comunitária, faz-se o uso dos elementos identificadores indicados por Raquel Paiva (2007) para esclarecer a presença da comunicação comunitária na atualidade. Esses pontos se encaixam como próximos das características do jornalismo cidadão.

O primeiro ponto indicado pela autora é que a comunicação comunitária se "constitui como uma força contra-hegemônica no campo comunicacional" (PAIVA, 2007, p. 137). Essa força de resistência também é uma característica do jornalismo de fonte aberta. A semelhança é evidente porque ambas as formas de comunicação têm por objetivo ser uma alternativa aos meios de comunicação tradicionais que possuem caráter mercantilista e empresarial.

Um segundo ponto que caracteriza a comunicação comunitária é que ela "atua na direção de uma estrutura polifônica” (PAIVA, 2007, p. 140) assim como atua o jornalismo cidadão. Essa, inclusive, é a característica mais gritante da forma de atuação jornalística, a multiplicidade de vozes é a ferramenta argumentativa daqueles que promovem a cidadania por meio do jornalismo. Tal característica é uma forma de incluir aqueles discursos que estão fora da mídia hegemônica.

No terceiro ponto indicado, a comunicação comunitária "produz novas formas de linguagens" (PAIVA, 2007, p. 141), assim como o jornalismo cidadão. Em ambos identifica-se uma multiplicidade de vocabulários e representações culturais amplas que definem novas linguagens e modos de fazer comunicação e os seus meios midiáticos. Uma redefinição dos sujeitos fazedores.

O quarto quesito é que a comunicação comunitária "capacita-se para interferir no sistema produtivo" (PAIVA, 2007, p. 142), assim como é capacitado o jornalismo cidadão, este mais que aquele. Quando as fontes é que produzem as informações sem uma figura intermediadora (jornalista, editor), ela já alterou drasticamente a rotina produtiva dos meios de comunicação. Nos meios comunitários, essa interferência é entre aqueles membros que são voluntários e os que recebem salários para realizarem determinadas atividades concebidas pela gestão comunitária.

Seguindo as definições propostas por Paiva (2007), temos o quinto ponto. Ela afirma que "comunicação comunitária gera uma estrutura mais integrada entre consumidores e produtores de mensagens" (PAIVA, 2007, p. 143). Elementos como interatividade e proximidade são pontos relevantes. Nada mais caracterizador do jornalismo cidadão do 
que a interatividade, principalmente com as ferramentas tecnológicas de comentários e outros aportes de contato que aproximam consideravelmente os produtores de informações e conteúdos.

Ainda nessa perspectiva de tecnologia, a outra semelhança apontada é justamente nessa linha. "A comunicação comunitária pode engendrar novas pesquisas tecnológicas" (PAIVA, 2007, p. 145). Esse desenvolvimento inclusive faz parte do surgimento do jornalismo cidadão, que se instaurou com a evolução da web. A alocação dessas ferramentas comunicacionais dentro da internet é outro facilitador para as transformações, mas não únicas. A contra-hegemonia também promove a criação de elementos voltados para a tecnologia que discordem dos meios de mercado tradicionais.

E por fim, como último caracterizador, a comunicação comunitária é tida como "um lugar propiciador de novas formas de reflexão sobre a comunicação" (PAIVA, 2007, p. 145). No jornalismo de fonte aberta, essa característica é a meta das discussões promovidas dentro dos espaços interativos. A promoção de reflexões e críticas faz das duas formas comunicacionais ferramentas de resistência às formas midiáticas desenvolvidas atualmente.

Esses pontos semelhantes indicam que ambas as formas comunicacionais estudadas têm o propósito de incentivar o desenvolvimento da cidadania de uma maneira mais democrática prezando pelo indivíduo e reforçando o poder do coletivo.

\section{Divergências: o que distancia essas formas comunicacionais}

Ressalta-se que a principal diferenciação entre os dois conceitos analisados é que a comunicação comunitária é diretamente vinculada à concepção de comunidade especificamente, as quais dividem características em comum. No jornalismo cidadão, essa delimitação de comunidade não é identificada e, pela maneira como se desenvolveu, também não é a intenção.

A próxima diferenciação observada foi no conceito de identidade. Na comunicação comunitária, é perceptível uma compreensão identitária em comum. Esta é dividida pelos membros que compõem a comunidade na qual o meio de comunicação está inserido ou o qual representa. Assim como não se pode delinear uma "formação identitária única" (TARGINO; CARVALHO; GOMES, 2008, p. 65) quando se diz respeito ao jornalismo de fonte aberta (cidadão). Para este, são muitos os indivíduos que postam as suas informações em um único meio de mídia e eles não seguem necessariamente uma linha identificadora convergente.

Seguindo entre os pontos que se constroem como divergentes em cada uma dessas formas, aponta-se a questão da educação. $\mathrm{Na}$ comunicação comunitária, esse elemento é fundamental. Conforme reforça Paiva (2007, p. 146), os meios desse tipo "atuam com o propósito primeiro da educação"; já no caso do jornalismo cidadão o propósito primeiro é permitir que o cidadão produza seus questionamentos e informações.

Um dos elementos que mais chamam a atenção na comunicação comunitária é que a própria comunidade tem a possibilidade de gerenciar seu meio de comunicação, seja uma rádio comunitária ou um jornal de bairro, dentre outras formas. Essa característica tão marcante que se configura inclusive como um dos níveis de participação (PERUZZO, 2006a) não é verificada necessariamente no jornalismo cidadão. No estudo de caso feito no CMI, os produtores de notícias não tinham a permissão de gerenciar o site em que postam seus conteúdos. Essa diferença se liga ao fato de os produtores não estarem constituídos em grupos ou comunidade, o que facilitaria a gestão de um meio de comunicação, mesmo que de pequeno porte.

Uma característica que também configura-se como fundamental na construção da comunicação comunitária é a escolha da programação ou da linha editorial do que é veiculado pelos meios midiáticos utilizados. Isso não se verifica no jornalismo cidadão. Nele, os "fazedores de notícias" (TARGINO, 2009, p. 53) não têm um espaço de discussão para que possam definir o que de fato é de interesse ou não e o que vai ser publicado. Em geral, as mídias cidadãs apresentam um livre espaço de publicações e de conteúdos. Esses conteúdos são de cunho político e reivindicatório, mas pontos como desenvolvimento e meio ambiente também são muito comuns.

No que diz respeito à questão de lócus de território, essa também é uma diferença. Para o jornalismo cidadão e a sua vinculação direta com o espaço da web, a noção física de território não é relevante, principalmente pela multiplicidade de 
suas fontes e os diferentes pontos geográficos em que eles se localizam. Nos meios comunitários, o território físico ainda é relevante, mas também já se encaminha para uma modificação.

Esses quesitos de diferenças mostram que o jornalismo e a comunicação social como um todo podem apropriar-se de muitas rotinas e de formas de fazer e, assim, ampliar os espaços de atuação e reconfigurarem os modos de fazer e os seus produtores.

\section{Considerações finais}

Em síntese, este trabalho foi uma revisita a conceitos clássicos sobre a comunicação comunitária e sobre o jornalismo cidadão, na tentativa de juntá-los de modo que fosse possível fazer um comparativo entre ambas as formas de desenvolvimento da comunicação e como acontece a produção de conteúdos para os meios midiáticos. Percebe-se que o desenvolvimento do jornalismo ruma para diversos caminhos e possui muitas formas de atuação, elemento visto nos dois conceitos apresentados, ligados especialmente à valorização do indivíduo e do coletivo que remam contra a maré dos meios de comunicações hegemônicos. Propõe-se uma nova maneira de produzir o jornalismo, potencializando a inserção das novas tecnologias e também de novas rotinas produtivas, tentando subverter a lógica do mercado.

Uma questão a considerar é que ambas as formas trabalhadas são fundamentadas em discursos teóricos válidos, que se encontram em pleno desenvolvimento. Muitos conceitos ainda serão e deverão ser acrescentados para que os estudos nessas áreas possam se consolidar, visando inclusive a novos formatos de jornalismo.

Tentou-se fazer, de um modo sistemático, um levantamento sobre as principais semelhanças e divergências entre a comunicação comunitária e o jornalismo cidadão, para que fosse possível compreender que pontos e que públicos são abarcados por essas formas comunicacionais. Além, é claro, de buscar entender o papel do novo produtor de notícias e conteúdos, mostrando que sua figura não elimina a necessidade do jornalista especializado.

Percebeu-se, contudo, que características tão marcantes desses meios como a participação por vias de mensagens e as produção de fontes abertas já estão sendo apropriadas pelos grandes meios de comunicação.
São cada vez mais comuns grandes portais noticiosos, rádios e canais de televisão utilizarem as informações e conteúdos produzidos pelos sujeitos e comunidades dentro de suas rotinas produtivas. Brittos (2006) reforça que essa característica apropriativa deriva do processo de globalização e horizontalidade dos conglomerados de mídia. Para esse autor, a apropriação se constitui como uma das características mais marcantes da fase da multiplicidade da oferta.

Todavia, essa apropriação não descaracteriza os formatos de comunicação debatidos, pois o proposto fundamental deles é a garantia das vozes populares. Com isso, compreender o desenvolvimento desses mecanismos comunicacionais e suas interfaces é crucial no entendimento das novas lógicas de mercado e suas constituições.

\section{Agradecimentos}

A Dai, pelo incentivo, a Samária, pela revisão, a Jennyfer e Clayton, pelas contribuições idiomáticas. À minha orientadora, Jacqueline Dourado, por ter me apresentado a Economia Política da Comunicação. E aos autores referenciados abaixo, por suas pesquisas.

\section{Referências}

BRITTOS, V. (Org.). Comunicação na fase da multiplicidade da oferta. Porto Alegre: Nova Prova, 2006.

FERREIRA DE MELO, L. D.; TORRES-MORALES, O. E. Rádio comunitária em Indaial, SC: aproximações e conceitos. 2007. Trabalho de Conclusão de Curso - Comunicação Social habilitação Publicidade e Propaganda, Universidade Regional de Blumenau (FURB), Santa Catarina, 2007. Disponível em: < http:/ / www.unicentro.br/redemc/2007/M\%C3\%8DDIA $\% 20$ CIDAD $\%$ C3\%83- $\% 20 \% 2016-\% 20 \mathrm{R} \% \mathrm{C} 3 \%$ A1dio $\% 20$ Comunit $\%$ C3\%A1 ria $\% 20$ em $\% 20$ Indaial $\% 20-\% 20$ Leticia $\% 20 \mathrm{e} \% 20 \mathrm{Of} \% \mathrm{C} 3 \%$ A 9 lia.pdf $>$. Acesso em: 30 julho 2011.

KPEROGI, F. Cooperation with the Corporation? CNN and the hegemonic cooptation of citizen journalism through iReport.com. Article. New Media e Socity, v. 13, n. 2, p. 314-329, 2011. 
MALINI, F. Modelos de colaboração nos meios sociais da internet: Uma análise a partir dos portais de jornalismo participativo. In: CONGRESSO BRASILEIRO DE CIÊNCIAS DA COMUNICAÇÃO, 1., 2008, Natal. Anais... Natal: Intercom, 2008. 1 CD ROM.

MORETZSOHN, S. O mito libertário do "jornalismo cidadão". Revista Comunicação e Sociedade, v. 9-10, p. 63-8, 2006.

PAIVA, R. Para reinterpretar a comunicação comunitária. In:PAIVA, R. O retorno da comunidade: os novos caminhos do social. Rio de Janeiro: MauadX, 2007. p. 133-148.

PERUZZO, C. M. K. Direito à comunicação comunitária, participação popular e cidadania. Revista Latinoamericana de Ciencias de la Comunicación, v. 2, n. 3, p. 18-41, 2005.

PERUZZO, C. M. K. Rádio Comunitária na internet: empodereamento social das novas tecnologias. Revista Famecos, n. 30, p. 115-125, 2006 a.
PERUZZO, C. M. K. Revisitando os Conceitos de Comunicação Popular, Alternativa e Comunitária. In: CONGRESSO BRASILEIRO DE CIÊNCIAS DA COMUNICAÇÃO, 29., 2006, Brasília. Anais... Brasília: Intercom, 2006b.

RABELO, D. C. Desafios: difundir-se e tornar-se comunitária. In: MARQUES DE MELO, J.; COBBI, M.C.; SATLER, L. (Org.). Mídia Cidadã-Utopia Brasileira. São Bernardo do Campo: UMESP, 2006.

TARGINO, M. das G. Jornalismo cidadão: informa ou deforma? Brasília: Ibict; UNESCO, 2009.

TARGINO, M.das G.; CARVALHO, C.P. de; GOMES, A. D. Centro de mídia independente Brasil: jornalismo cidadão e democracia representativa. Revista Comunicação e Inovação, v. 9, n. 16, 2008. Disponível em: < http:/ / seer. uscs.edu.br/index.php/revista_comunicacao_inovacao/ article/view/700>. Acesso em: 20 nov. 2011.

WOLF, M. Teorias da comunicação. Lisboa: Presença, 1987.

Recebido: 27/02/2012

Received: 02/27/2012

Aprovado: 26/03/2012 Approved: 03/26/2012 